\title{
Securitização das Mudanças Climáticas: O Papel da União Europela*
}

Luciana Mendes Barbosa** e Matilde de Souza***

\section{Introdução}

Até meados da década de 1980, o problema das mudanças climáticas era praticamente desconhecido, circulando apenas por ambientes acadêmicos e políticos. Essa temática passou a figurar na agenda das relações internacionais a partir da criação do Intergovernmental Panel on Climate Change (IPCC) em 1988, da adoção da Convenção do Clima em 1992 e do Protocolo de Quioto em 1997.

\footnotetext{
* Artigo recebido em março e aprovado para publicação em maio de 2010. Trabalho realizado com o apoio do Conselho Nacional de Desenvolvimento Científico e Tecnológico (CNPq).

** Mestre em Relações Internacionais pela Pontifícia Universidade Católica de Minas Gerais (PUC-Minas) e analista de projetos do Grupo Interdisciplinar de Aplicação à Aprendizagem. E-mail: lucianabarbosa@gmail.com.

*** Doutora em Ciência Política pela Universidade Federal de Minas Gerais (UFMG) e professora do Programa de Pós-Graduação em Relações Internacionais da PUC-Minas. E-mail: matilde@ pucminas.br.
}

CONTEXTO INTERNACIONAL Rio de Janeiro, vol. 32, n 1, janeiro/junho 2010, p. 121-153. 
Com o desenlace de três importantes eventos em 2007 - a publicação do Quarto Relatório de Avaliação do IPCC, a primeira reunião do Conselho de Segurança para debater o tema e a concessão do Prêmio Nobel da Paz ao IPCC e ao ex-vice-presidente dos Estados Unidos, Al Gore -, os efeitos das mudanças climáticas começaram a ser tratados como questão de segurança internacional, fato que indica um processo de construção das mudanças climáticas como ameaça à paz e à segurança internacionais.

Desde a politização dos problemas ambientais na década de 1970, surgem apelos à sua securitização, ilustrados pela publicação dos artigos de Richard Ullman (1983), Jessica Mathews (1989) e Norman Myers (1989), alertando para a necessidade de redefinição do conceito de segurança para a inclusão das mudanças ambientais. Com o fim da Guerra Fria, este tema passa a interessar aos estudos de segurança sobre a emergência de novas ameaças e a necessidade de expansão da agenda. A integração entre essas temáticas se realizou de modo mais efetivo com a publicação da obra de Buzan, Waever e Wilde (1998), na qual os autores propõem a elaboração de quadros analíticos específicos para cada um dos setores de segurança, com a construção de suas próprias regras, atores, discursos e objetos de referência.

Contudo, o entendimento da relação entre degradação ambiental e estabilidade política não é homogêneo e tem se realizado a partir de premissas distintas, indicando duas abordagens gerais. A primeira baseia-se na ideia de conflito ambiental, fundamentada no conceito de escassez/abundância de recursos naturais, responsável pelo desencadeamento de conflitos. Essa perspectiva se realiza pelos pressupostos tradicionais de segurança, sendo que a soberania e a integridade territorial do Estado são seus principais eixos. A segunda problematiza o conceito de soberania estatal, referindo-se ao modo como as mudanças no meio ambiente afetam também os indivíduos, integrando tendência recente: a segurança humana. 
Securitização das Mudanças Climáticas: 0

Papel da União Europeia

Essa temática foi levada pela primeira vez ao Conselho de Segurança (CS) em 2007, com o propósito de debater as suas consequências para a paz e a segurança internacionais. Em documento, o Reino Unido afirmava que as mudanças climáticas ameaçavam a paz e a segurança internacionais em função de seus efeitos sobre litígios já existentes, envolvendo países fronteiriços, além de constituir um fator desencadeador de crises humanitárias, disputas por recursos escassos e tensões sociais (SECURITY COUNCIL, 2007a). Durante o debate, a então secretária de Relações Exteriores do Reino Unido, Margareth Beckett, declarou que as mudanças climáticas se referiam não à questão de segurança nacional, mas à "segurança coletiva em um mundo frágil e crescentemente interdependente", transformando assim "o modo como a comunidade internacional pensa a segurança" (SECURITY COUNCIL, 2007b, p. 19). ${ }^{1}$

Esse debate no CS integra uma cadeia discursiva na qual as mudanças climáticas têm sido apresentadas como um problema de segurança nacional e internacional. ${ }^{2}$ Assim, parece indispensável discutir: quais critérios permitem identificar o principal ator securitizador das mudanças climáticas no sistema internacional? De que modo este ator conseguiu mobilizar a audiência? Esse processo foi capaz de transformar as comunidades políticas, institucionalizando as mudanças climáticas como um problema de segurança? Ou esse processo ainda está em construção?

Para a compreensão dessas questões, é necessário um histórico dos discursos securitizadores das mudanças climáticas, permitindo entendimento das comunidades políticas sobre as consequências das mudanças climáticas, no qual a consciência das questões ambientais, a convergência de agendas parcialmente incompatíveis, que, combinadas, produziram o efeito securitizador, e a redução gradual das incertezas sobre o aquecimento global desempenham um relevante papel (WAEVER, 2009). 
A teoria da securitização informa os critérios que permitem designar a União Europeia (UE) como principal ator securitizador das mudanças climáticas, assim como os discursos que contribuíram para a mobilização da audiência. Além de mapear esse processo, este trabalho buscou compreender as concepções de segurança que informam os discursos da UE, revelando, desse modo, uma multiplicidade de práticas que apontam as possibilidades e os limites da teoria de securitização para a análise de novas ameaças à segurança.

\section{Repensando segurança: a Escola de Copenhague e a teoria de securitização}

Durante o período da Guerra Fria, o conceito de segurança foi central para os estudos de política internacional, até então focados nas questões militares e no uso da força. Os aspectos não militares da segurança passaram a adquirir maior visibilidade com as transformações globais em curso desde a década de 1970 e a emergência de uma ampla agenda de segurança nos anos 1980. Após a Guerra Fria, as críticas sobre a primazia da segurança militar asseveraram-se, resultando na fragmentação dos debates em três perspectivas: a tradicionalista, cujo foco principal é militar; a abrangente, partidária da expansão horizontal do conceito e da incorporação de outros setores para além do militar; e a corrente crítica, denominada Estudos de Segurança Crítica, que questiona o quadro no qual a segurança é conceituada, expandindo a agenda vertical e horizontalmente (BUZAN, 1997).

Para a abordagem abrangente, segurança é uma forma específica de práxis social; segurança é "what actors make of it" (WENDT, 1999; BRAUCH, 2007; HUYSMANS, 2002) ou "o modo como é socialmente constituída a natureza das questões" (BUZAN et al., 1998, p. 203). 
Securitização das Mudanças Climáticas: 0

Papel da União Europeia

Entre os principais formuladores da abordagem abrangente, encontra-se a Escola de Copenhague, um corpo de pesquisa associado principalmente aos trabalhos de Barry Buzan e Ole Waever, que têm desenvolvido um instrumento analítico relevante: a Teoria da Securitização. Essa teoria destaca a natureza política do "fazer" segurança, desafiando a abordagem tradicional de segurança, preocupada com ameaças autoevidentes, e introduzindo uma perspectiva social construtivista.

Todavia, apesar desse caráter, a abordagem da Escola de Copenhague não pode ser considerada uniformemente distribuída: enquanto seu entendimento sobre segurança é radicalmente construtivista, sua interpretação das relações sociais não o é. Ainda que o construtivismo ontológico preconize que as relações sociais não são um produto da natureza, mas fruto das ações humanas, sempre sujeitas a mudanças, os teóricos de Copenhague admitem que nem todas as práticas sociais são igualmente maleáveis. Algumas práticas estão profundamente sedimentadas e não podem ser consideradas uma questão de escolha (BUZAN et al., 1998; HUYSMANS, 1998).

É justamente nesse ponto que residem as tensões relativas à teoria de securitização, expondo análises empíricas de objetos não convencionais de segurança, como as mudanças climáticas, a consequências problemáticas (STRITZEL, 2007; TROMBETTA, 2008a). Isso porque o conceito de segurança traz consigo um conjunto de práticas e um modo de lidar com o problema proveniente do entendimento schimmitiano do político. Contudo, a emergência de novas ameaças, especialmente as ambientais, tem sugerido que medidas reativas e o entendimento antagonista da segurança não são os únicos modos de lidar com essas novas questões, uma vez que medidas preventivas e o fortalecimento do multilateralismo têm emergido como práticas viáveis.

Segurança, na perspectiva dos teóricos da Escola de Copenhague, pode ser entendida como uma forma particular de prática social, re- 
sultado dos atos de fala proferidos por um enunciador - um ator securitizador - que apresenta uma dada questão como ameaça existencial a um objeto de referência, reivindicando a adoção de medidas excepcionais e urgentes na tentativa de contê-la. É preciso observar as qualidades específicas que caracterizam os problemas de segurança: o sentido de urgência, a reivindicação do uso de meios extraordinário-excepcionais de segurança e a construção de uma ameaça existencial a um objeto de referência (BUZAN et al., 1998).

A teoria de securitização deve ser entendida como o estudo de ameaças subjetivas, definidas em um processo intersubjetivo de construção de entendimentos sobre a realidade. Para isso, o analista deve estudar a construção da ameaça por meio da lógica de securitização e de seus efeitos (BUZAN et al., 1998). Nessa perspectiva, repousa uma estrutura teórica para os estudos de securitização e os conceitos em torno dos quais a teoria se desenvolve: movimento de securitização, atos de fala, ator securitizador, objeto de referência, entre outros.

Uma maneira de identificar o ator securitizador é o estudo da lógica de securitização, sendo importante verificar de que lugar este ator está falando, se como indivíduo ou se em nome de uma estrutura organizacional. Isso pode ser especialmente difícil quando se faz referência a questões ambientais, pois estas não se agrupam em uma estrutura organizacional com porta-vozes estabelecidos, o que cria problemas para a legitimação de discursos proferidos por atores não estatais (BUZAN et al., 1998).

De acordo com Buzan et al. (1998), o termo securitização pode ser entendido como um processo no qual determinados temas passam a integrar a agenda de segurança, de modo que:

"Segurança" é o movimento que trata a política para além das regras do jogo estabelecidas e enquadra a questão ou como um tipo particular de política, ou como algo que a transcende. A securitização pode então ser vista como uma 
Securitização das Mudanças Climáticas: 0

Papel da União Europeia

versão extrema da politização. Teoricamente, qualquer questão pública pode ser localizada no espectro que varia do "não politizado" [...], passando pelo "politizado" [...], alcançando o "securitizado" (BUZAN et al., 1998, p. 23-24).

O processo de securitização pode ser entendido como aquele em que um dado objeto de referência é tratado por determinado ator - $\mathrm{o}$ ator securitizador - como se estivesse sob uma ameaça existencial. $\mathrm{O}$ ator securitizador passa a reivindicar junto à audiência o uso extraordinário da força e a adoção de medidas emergenciais para conter a ameaça. Nesse processo, a questão é retirada da esfera da política, podendo então ser localizada em um espectro que varia da securitização $a d$ $h o c$, passa pela securitização, até atingir a institucionalização, fase na qual todo o processo é normalizado e se torna parte de um discurso político padrão (VAN DIJCK, 2006; BUZAN et al., 1998).

\section{Segurança ambiental: entre as perspectivas nacional e humana}

É na década de 1970 que as discussões sobre meio ambiente deixam de pertencer exclusivamente ao ambientalismo, para integrar-se aos estudos de segurança. Teórico pioneiro nesta fase foi Lester Brown (1977), que publicou na década de 1970 o texto Redefining national security. Esse tema foi retomado em 1983, com a publicação do artigo "Redefining security", de Richard Ullman. Outro fator que colaborou para a inserção dos problemas ambientais no debate sobre segurança foi a publicação do Relatório Brundland em 1987, que afirmava que "a noção de segurança, tal como é tradicionalmente entendida [...] tem de ser ampliada para abranger os efeitos cada vez mais graves do desgaste ambiental - em nível local, nacional, regional e mundial" (CMMAD, 1991, p. 21). 
Para a Comissão Mundial sobre Meio Ambiente e Desenvolvimento (CMMAD), segurança ambiental tem como objeto de referência a soberania estatal e pode ser enquadrada na perspectiva nacional abrangente dos estudos de segurança. Para a redução das ameaças à segurança, o relatório recomenda a redefinição de prioridades em escalas nacional e global, que deveria incluir a adoção de concepções mais abrangentes de segurança, com o abandono da lógica armamentista e a concentração de esforços na construção de um futuro comum (CMMAD, 1991, p. 325-344). Para que tal mudança fosse plausível, a comissão cunhou o termo "insegurança ambiental", que tem como objetivo repensar o vínculo entre meio ambiente e segurança (TRENELL, 2006, p. 12).

A lógica fundamental dos discursos sobre segurança ambiental, destacou Wilde (2008), funda-se na concepção de que a humanidade está vivendo para além da capacidade de suporte dos ecossistemas terrestres, em escala local, regional e global. Para o autor, a essência destes discursos é avaliar a relação entre a degradação ambiental e a estabilidade política. As discussões em torno dessa relação abrigam dois entendimentos principais sobre ela: a perspectiva nacional e a de segurança humana. Esta última integra um panorama mais amplo, que Page (2000) denomina uma abordagem abrangente e profunda de segurança, em virtude da sua abrangência horizontal (setorialização) e vertical dos objetos e práticas de segurança.

A visão tradicional da segurança ambiental é orientada tanto pela ideia de escassez, quanto pela noção de abundância de recursos naturais. Esta perspectiva, comumente denominada de "conflito ambiental", norteia-se pelos pressupostos tradicionais de segurança, segundo os quais a soberania e integridade territorial do Estado são o epicentro das preocupações com segurança. Para Ullman (1983 apud PAGE, 2000, p. 36): ou sequência de eventos que (1) ameaça drasti- 
Securitização das Mudanças Climáticas: 0

Papel da União Europeia

\section{Figura 1}

Relação entre Segurança, Meio Ambiente e suas Variações Conceituais

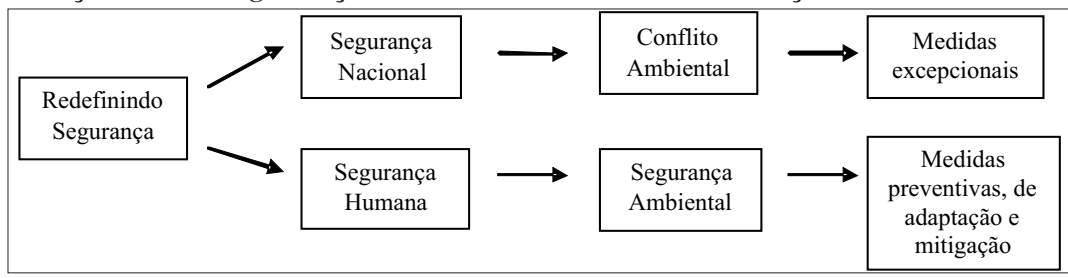

Fonte: Barnett (2001).

camente, e sobre um período relativamente curto de tempo, degradar a qualidade de vida dos habitantes de um Estado, ou (2) ameaça de modo significativo limitar a variedade de escolhas políticas disponíveis para o governo de um Estado ou para entidades privadas não governamentais (pessoas, grupos, corporações) dentro do Estado.

Contudo, mesmo sendo um defensor da perspectiva estatal de segurança, Ullman (1983 apud PAGE, 2000, p. 36) pondera, afirmando que "definir segurança nacional [...] meramente em termos militares transmite uma imagem profundamente falsa da realidade". A segunda perspectiva refere-se ao modo como as mudanças no meio ambiente afetam não só a segurança dos Estados, mas também a dos indivíduos, integrando desse modo a perspectiva já vista anteriormente da "segurança humana". De acordo com Brauch (2005, p. 34), "o conceito de segurança ambiental centrado no humano" firma-se sobre justificativas morais e pragmáticas, visto que seu foco principal é o bem-estar dos indivíduos, principalmente a proteção dos direitos dos indivíduos mais vulneráveis da sociedade contra a degradação ambiental. Nesse sentido, a abordagem da segurança ambiental é relevante por dois motivos. Primeiro, porque ela mesma pode ser a origem da insegurança; e, segundo, porque determinados tipos de alterações no meio ambiente podem exacerbar outras formas potenciais de insegurança, tais como a pobreza, a discriminação e até mesmo o terrorismo (DABELKO et al., 2000). 


\section{"Garantir a segurança em um mundo em mudança": 0 protagonismo da União Europeia no processo de securitização das mudanças climáticas}

A UE, em especial a Comissão Europeia, tem insistido amplamente na relação entre os problemas ambientais globais e a probabilidade de países em conflito exportarem suas divergências para dentro da

\section{Figura 2}

Principais Paradigmas da Segurança Ambiental

SEGURANCYA AMBIENTAL: ENTRE OS PARADIGMAS NACIONAL E HUMANO

Q1 - O que são e quem são os agentes do discurso de segurança?

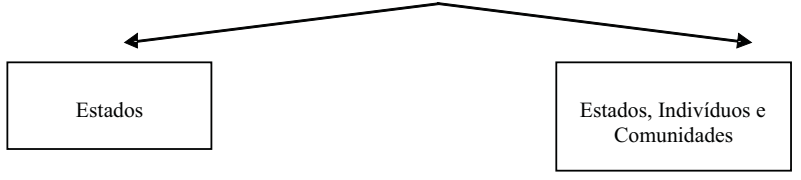

Paradigma da Segurança Nacional

Paradigma da Segurança Humana

Q2 - Quais fenômenos deveriam ser considerados como uma ameaça potencial à segurança?

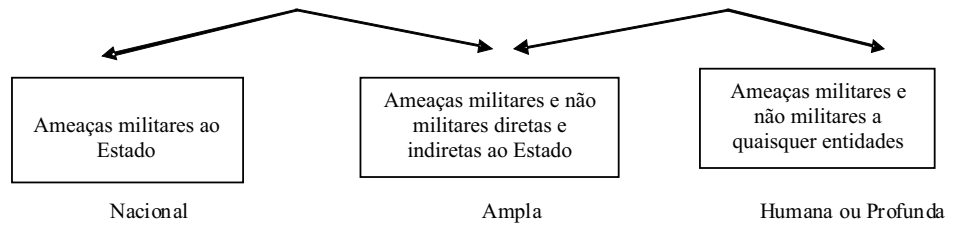

Q3 - As mudanças ambientais constituem uma ameaça aos objetos referentes no discurso de segurança?

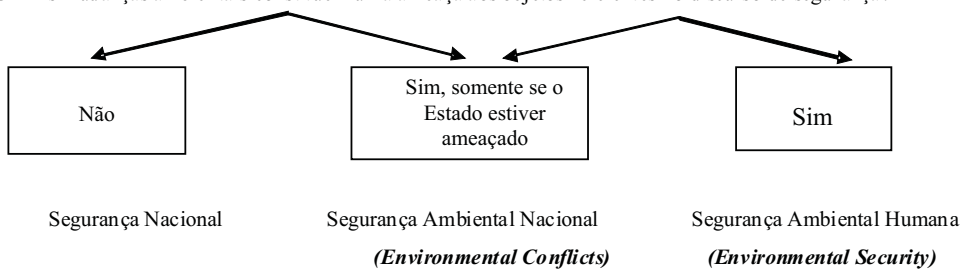

Fonte: Page (2000). 
Securitização das Mudanças Climáticas: 0

Papel da União Europeia

fronteira europeia. Um dos divisores de águas dessa abordagem foi a criação, em 2003, da Estratégia Europeia de Segurança (EES), cuja política integrada de segurança reuniu a prevenção de conflitos, a gestão de crises, o multilateralismo efetivo, além de integrar novas ameaças, tais como terrorismo, crime organizado, migrações ilegais e o aquecimento global.

A adoção da EES é uma das primeiras tentativas de securitização do clima, visto que as alterações climáticas já eram preocupação, ao lado de outras ameaças como "a guerra contra o terror", "os Estados fracassados" (failed states) e a "migração descontrolada", formando um continuum de segurança. ${ }^{3}$ Contudo, as mudanças climáticas só seriam definitivamente integradas à política de segurança europeia no ano de 2008, com o Relatório sobre a Execução da Estratégia Europeia de Segurança, cuja proposta é "incorporar ameaças mais complexas" que, "como o aquecimento global e a degradação ambiental, estão a mudar a face do planeta", ameaçando a UE, que julga ser "um polo de estabilidade" (CONSELHO DA UNIÃO EUROPEIA, 2008, p. 1).

Tais tentativas da UE de construção de um entendimento comum sobre essa questão permitem considerá-la como o principal ator securitizador do clima: a UE já possui uma liderança consolidada na condução da política climática internacional, ocupa posição de destaque como ator global no sistema internacional e tem obtido resposta positiva da audiência interna e externa.

Apesar dos esforços da Alemanha e do Reino Unido em inserir as mudanças climáticas na agenda do CS, suas ações não conseguiram superar o protagonismo da UE na liderança do processo de securitização do clima. A UE traz consigo autoridade e audiência "enquanto estruturas sociais eficazes dentro das quais uma variedade de atores securitizadores pode experimentá-las com melhores chances de su- 
cesso, ao invés do que sua posição individual, por si só, lhes daria" (BUZAN; WAEVER, 2009, p. 14).

A Comissão Europeia e o alto representante, Javier Solana, prepararam, em junho de 2007, um relatório conjunto sobre "alterações climáticas e segurança internacional" para o Conselho Europeu. Nele, a UE apresentou a possibilidade de conjugação de todos os seus instrumentos com o propósito de enfrentar os riscos de segurança apresentados pelas mudanças climáticas. Embora voltada para as consequências das alterações climáticas para a segurança internacional, "a resposta da UE será condicionada pelo impacto das alterações climáticas na Europa propriamente dita" (COMISSÃO EUROPEIA, 2007, p. 3). Neste ponto, a securitização tem uma dimensão política, já que as mudanças climáticas formam uma ameaça à capacidade política dos Estados-membros de controlar seus próprios territórios, visto que "os vizinhos da UE incluem algumas das regiões mais vulneráveis às alterações climáticas, como o Norte da África e o Médio Oriente", tornando possível um aumento da "pressão migratória nas fronteiras da União Europeia, a instabilidade política e os conflitos. Esta situação poderá também ter um impacto significativo nas rotas de aprovisionamento energético da Europa" (COMISSÃO EUROPEIA, 2007, p. 6). Como resultado, os Estados-membros enfatizam o desenvolvimento de ações que visem:

A intensificação das capacidades da UE em termos de investigação, análise, vigilância e alerta precoce, e elaboração de Listas de Observação que envolva, designadamente, o Instituto de Estudos de Segurança, o Centro de Satélites da UE (CSUE), o Centro de Situação Conjunto da UE (SITCEN), a Rede Europeia de Correspondentes de Segurança Energética (NESCO), a Iniciativa "Vigilância Global do Ambiente e da Segurança" e os Centros Comuns de Investigação [...]; Intensificação do planejamento das ações e das capacidades da UE e dos Esta- 
Securitização das Mudanças Climáticas: 0

Papel da União Europeia

dos-membros, inclusive no domínio da proteção civil, e da utilização de instrumentos (civis e militares) de gestão de crises e de resposta às catástrofes, de forma a contribuir para fazer face aos riscos que as alterações climáticas provocam em termos de segurança; Continuação dos trabalhos desenvolvidos pela Comissão a fim de analisar mais circunstanciadamente, região a região, quais as implicações prováveis em termos de segurança e a forma como os interesses da UE serão afetados (COMISSÃO EUROPEIA, 2007, p. 9-10).

Um discurso que consolida essa percepção é o do Relatório sobre a Execução da Estratégia Europeia de Segurança: Garantir a Segurança num Mundo em Mudança, no qual o Conselho Europeu admite que "as alterações climáticas podem também despoletar conflitos a propósito de rotas comerciais, zonas marítimas e recursos anteriormente inacessíveis", havendo a necessidade, então, de reforçar as "capacidades de prevenção de conflitos e de gestão de crises, mas é necessário fazê-lo também no que toca à capacidade de análise e de alerta rápido" (CONSELHO DA UNIÃO EUROPEIA, 2008, p. $5-6)$.

Em relação à sensibilização da audiência, os europeus têm obtido sucesso. Em estudo qualitativo realizado a pedido da Comissão Europeia em 2006 com os 25 Estados-membros da UE à época, as mudanças climáticas aparecem como uma das principais preocupações, em virtude dos "riscos das ameaças ambientais para o futuro do mundo (catástrofes naturais ou nucleares e os efeitos das mudanças climáticas)" (EUROBARÔMETRO, 2006, p. 8).

Pesquisas de opinião realizadas na Europa expressam o impacto desses discursos securitizadores. Pesquisa realizada em 2007 mostrou que $90 \%$ dos entrevistados compartilhavam essa opinião; $57 \%$ dos entrevistados consideravam que essa questão deveria ser tratada com 
muita urgência, situação destacada pelos pesquisadores responsáveis como incomum (EUROBARÔMETRO, 2008). Em 2008, a pesquisa "As atitudes dos europeus em relação às mudanças climáticas" revelou tendência semelhante: $60 \%$ dos entrevistados confirmaram que as mudanças climáticas figuravam como o mais grave problema enfrentado pelo mundo na atualidade. Comparados aos 53\% que consideravam o terrorismo internacional e aos $38 \%$ que consideravam os conflitos armados como os problemas mais graves, essa pesquisa manifestou uma mudança de perspectiva bastante significativa em relação à relevância das mudanças climáticas (EUROBARÔMETRO, 2008, p. 12). Outras pesquisas de opinião indicaram tendências semelhantes, como as pesquisas realizadas pela Ipsos Mori (2007), pela Transatlantic Trends (2007) e pela UNEP (2008), entre outras.

Considerando as pesquisas de opinião, é possível afirmar que o movimento de securitização atingiu de modo parcial a audiência em escala mundial, sendo mais bem-sucedido na Europa. Contudo, apesar das constantes referências ao clima como ameaça global, a resposta externa não é homogênea. O debate no Conselho de Segurança revela que parte considerável da audiência se mostrou desfavorável ao estabelecimento da relação entre segurança e mudanças climáticas e, consequentemente, às pretensões dos europeus de inserção desta questão no CS.

Além da legitimação e incentivos da audiência, especialmente europeia, aos movimentos securitizadores das mudanças climáticas protagonizados pela UE, três motivações políticas devem ser consideradas. Primeiro, a política climática tem se tornado um importante condutor da integração europeia em geral. De acordo com Oberthür e Kelly (2008), tanto o fracasso da Política Comum de Segurança e Relações Externas (em inglês, Common Foreign and Security Policy (CFSP)) no direcionamento do processo de invasão do Iraque em 2003, quanto a falha no estabelecimento de uma Constituição para a Europa em 2005 levaram as instituições europeias a procurarem 
Securitização das Mudanças Climáticas: 0

Papel da União Europeia

oportunidades para reforçar sua legitimidade e revigorar seu processo de integração. Dado que a proteção ao meio ambiente vem recebendo atenção da opinião pública europeia nas últimas duas décadas, associada à urgência e importância atribuídas às mudanças climáticas pelo Quarto Relatório do IPCC (2007), a UE tem encontrado grande motivação para atuação neste campo. Nesse sentido, os fracassos acima aludidos são contrastados com o sucesso da UE no resgate do Protocolo de Quioto em 2001, ameaçado pela oposição explícita dos Estados Unidos à sua ratificação.

Em segundo lugar, a intensificação das discussões acerca do futuro da segurança energética na Europa favorece o desenvolvimento de uma política climática mais rigorosa. Verifica-se a evidente dependência da UE em relação à importação de combustíveis, o aumento significativo nos preços do petróleo e gás e desdobramentos políticos no Oriente Médio e na Rússia. A agenda de segurança energética, resultante desses fenômenos, reforça a agenda climática, especialmente no que diz respeito às políticas voltadas para a eficiência energética e fontes alternativas, além de reformas significativas no mercado energético (TROMBETTA, 2008a).

Como a questão energética tem sido tradicionalmente considerada uma prerrogativa dos Estados-membros, e a segurança quanto aos suprimentos de energia uma questão de segurança nacional, a securitização de ambos tem contribuído para o desenvolvimento de uma política energética comum e uma estratégia de segurança que designadamente reflete as capacidades da UE. De maneira surpreendentemente oposta a uma abordagem antagonista, essa questão tem repousado sobre a liberalização e a cooperação com vistas a assegurar suprimentos energéticos e a estabilidade climática.

O impacto dessa estratégia tornou-se evidente pela reação da Comissão Europeia durante a crise do gás ocorrida entre a Ucrânia e a Rússia em 2006: 
Quando a Rússia, envolvida na disputa sobre o preço do gás com a Ucrânia, efetuou o corte no suprimento de gás para a última, a quantidade de gás transitando pela Ucrânia e destinado para a Europa declinou drasticamente (Stern 2006). Esta situação foi considerada um despertar que instigou um amplo debate sobre a segurança energética. Enquanto dentro da OTAN a questão foi discutida em termos de novas alianças, incluindo a possibilidade de envolvimento militar para patrulhar as rotas de abastecimento, sugerindo uma abordagem antagonística (Shea 2006), dentro da UE a crise proporcionou uma oportunidade de acelerar o desenvolvimento de uma política energética comum (TROMBETTA, 2008a, p. 12).

Essa política energética estabeleceu objetivos ambiciosos, mobilizando consensos por meio de um duplo aparato: a segurança climática e a segurança energética. Em janeiro de 2007, a Comissão Europeia apresentou o Pacote de Energia e Clima, que incluía a revisão da estratégia energética, focando nos aspectos internos e externos da política energética da União Europeia. Alguns meses depois, em março de 2007, a UE aprovou o plano, concordando com a redução de $20 \%$ nas taxas de emissões de gases de efeito estufa até 2020, ano base de 1990.

Em terceiro lugar, a posição da UE no sistema internacional e sua orientação estratégica nas relações internacionais, incluindo seu forte incentivo ao multilateralismo, também contribuíram para sustentar a liderança da UE na política climática internacional e consequentemente no movimento de securitização do clima (OBERTHÜR; KELLY, 2008).

É justamente por causa desse objetivo de fortalecer seu papel como ator global que a UE também tem priorizado a adoção de uma abordagem mais amena, baseada na prevenção, em detrimento de uma 
Securitização das Mudanças Climáticas: 0

Papel da União Europeia

abordagem reativa. Contudo, a manutenção desse balanceamento representa um desafio para a UE na condução do processo de securitização do clima, visto que envolve questões energéticas de um lado, tradicionalmente tratadas pela lógica da segurança nacional, e questões climáticas de outro, recentemente tratadas pela perspectiva $h u$ man-centred de segurança. Além disso, para o equacionamento desse dilema, deve-se ter em conta também que o movimento de securitização, conduzido pela Europa, ganha relevo em um contexto de "guerra contra o terror", sugerindo, por outro lado, o emprego de meios tradicionais de segurança e de uma linguagem de violência e inimizade para justificar ações antecipatórias de combate à insegurança energética e climática (TROMBETTA, 2008a).

\section{As mudanças climáticas, a União Europeia e o desafio à lógica de segurança}

Ao tentar compreender as diferentes concepções de segurança que informam os discursos dos atores securitizadores do clima, este trabalho se deparou com uma multiplicidade de práticas, que colocaram em evidência as possibilidades e os limites referentes à teoria de securitização e ao próprio objeto, bem como os dilemas que os percorrem.

Tendo em vista o potencial da securitização para reforçar a questão das mudanças climáticas internacionalmente pela sensibilização e destinação de recursos, poderia se esperar, contudo, que a linguagem de segurança conduzisse a respostas simultaneamente afastadas da esfera de cooperação internacional e próximas a organizações militares e de inteligência, com o poder de coagir aqueles Estados que se recusassem a reduzir suas emissões de gases de efeito estufa. Seria de se esperar, ainda, que a racionalidade de segurança, orientada pela lógica ameaça/defesa, colocasse em jogo os esforços internacionais para solucionar o problema das mudanças climáticas, (i) em função 
de interesses nacionais estreitos e em detrimento da cooperação internacional, (ii) que permitissem que os Estados priorizassem os recursos destinados ao combate às mudanças climáticas para suas forças armadas e elites, cujo papel é crucial para a manutenção da segurança doméstica, e (iii) porque, ao retratar as mudanças climáticas como ameaça existencial, esta lógica trabalharia na contramão dos esforços em curso para a realização de um acordo que substituirá o Protocolo de Quioto, em 2012.

Contudo, tais possibilidades teóricas revelaram a existência de tensões entre uma lógica de segurança baseada na prevenção de conflitos, na gestão de riscos e no multilateralismo, orientadora dos discursos dos principais atores securitizadores do clima, e uma lógica orientada por práticas embasadas no excepcionalismo das medidas propostas e no antagonismo entre atores, preconizada pela teoria de securitização. A principal ambiguidade reside, portanto, na lógica de segurança.

Segundo Buzan et al. (1998, p. 5), a categoria segurança traz consigo um conjunto de práticas e um modo de lidar com determinado tema, imprimindo-lhe lógica e racionalidades específicas, submetendo-o a atitudes decisionistas (decisionist attitude), cuja ênfase recai sobre a importância de medidas emergenciais e reativas que, uma vez acionadas, não estão abertas à negociação. Tal lógica seria inspirada no entendimento schmittiano do político, o que tornaria a lógica de segurança uma lógica da guerra, o que sugere forma extrema de oposicionismo, um jogo de soma zero no entendimento sobre segurança. Um performativo de segurança tem que levar em consideração esse antagonismo. Essa concepção relativa a uma lógica antagonista da política é a mesma que orienta o caráter fixo das práticas de segurança, preconizado por Waever (1995a, 1995b) e Buzan et al. (1998) na teoria de securitização, limitando a historiar segurança e a analisar a transformação das unidades de segurança (TROMBETTA, 2006). 
Securitização das Mudanças Climáticas: 0

Papel da União Europeia

A institucionalização do discurso nacional de segurança fez com que essa racionalidade restrita a contextos específicos passasse a se propagar em diferentes setores, dos quais vinha se mantendo distante no período da Guerra Fria (BUZAN et al., 1998; TROMBETTA, 2006), colocando em evidência "os problemas da securitização, quando o meio ambiente está envolvido" (TROMBETTA, 2006, p. 8). Nesse sentido, a securitização dos problemas ambientais torna-se problemática justamente por causa do conjunto de práticas que supõe representar.

Para a Escola de Copenhague, segurança "carrega consigo uma história e um conjunto de conotações dos quais não se pode escapar" (WAEVER, 1995a, p. 47), ou seja, enquanto a securitização constitui uma escolha política, as práticas envolvidas em tal processo não o são. Por conseguinte, estes autores consideram a transformação de uma questão em problema de segurança uma opção pouco proveitosa ou desejável, especialmente no campo ambiental, visto que, "quando se considera o movimento de securitização, é preciso levar em conta o efeito sempre problemático de aplicar uma mentalidade de segurança contra as possíveis vantagens de enfoque, atenção e mobilização inerentes à politização (BUZAN et al., 1998, p. 29). Com efeito, Buzan et al. (1998) deixam clara sua opção (normativa) pela dessecuritização, visto que há a transformação da lógica orientada pela "sequência ameaça-defesa em direção à esfera pública ordinária", caracterizada pelo diálogo e decisões abertas (BUZAN et al., 1998, p. 29), cujo slogan é "menos segurança, mais política" (WAEVER, 1995a, p. 56). No entanto, o que se observa é que as tendências para as quais aponta o movimento de securitização das mudanças climáticas indicam várias tentativas de evocação do "poder simbólico de um discurso ambiental baseado na interdependência e na prevenção para estabelecer uma gestão de segurança em escala global" (TROMBETTA, 2008a, p. 13).

É nesse sentido que as mudanças climáticas têm desafiado a lógica de securitização característica da Escola de Copenhague. Em primeiro 
lugar, pelo desafio à identificação do objeto referente de segurança. O clima em si mesmo não é o referente de segurança, pelo contrário, em geral alude-se a coletividades humanas que dependem da estabilidade climática. Nesse sentido, representar as mudanças climáticas como ameaça a toda humanidade sugere a possibilidade de criação de uma comunidade global, visto que "ameaças criam uma sociedade e ameaças globais criam uma sociedade global" (BECK, 2000 apud TROMBETTA, 2006, p. 5). Uma vez que a possibilidade da existência de uma comunidade global começa a emergir, o processo de securitização pode ser encarado como parte de um amplo processo de transformação das comunidades políticas.

Em segundo lugar, destaca-se o problema de identificação do inimigo. Muitos problemas ambientais, incluindo as mudanças climáticas, podem afetar toda a humanidade. Contudo, sendo praticamente inviáveis a criação de barreiras e o distanciamento de tais problemas, como então os discursos securitizadores do clima podem ser interpretados tendo em vista uma lógica cujo critério de definição é a existência de antagonismos entre amigos e inimigos? Visto que a lógica schmittiana se refere a comunidades humanas e não a processos físicos ou naturais, transformar a natureza ou processos naturais - físicos - em inimigos não seria, no mínimo, problemático? Em terceiro lugar, ao sugerir que a análise do processo de securitização deva orientar-se por práticas de segurança estáveis, com vistas à necessidade de contornar as características e consequências da securitização, Buzan et al. (1998) acabam por contrariar os pressupostos que deram origem à teoria de securitização. De acordo com estes, a securitização, enquanto um ato de fala performativo, presume que, ao dizer algo, algo é feito e o contexto é transformado. Nesse sentido, a comunicação seria mais do que a transmissão de um significado dependente da intenção do enunciador, mas um processo comunicativo e interativo que independe da intenção ou do contexto no qual está inserido o ator. Nessa perspectiva, a segurança estaria associada a significa- 
Securitização das Mudanças Climáticas: 0

Papel da União Europeia

dos específicos e práticas específicas, de caráter não fixo (TROMBETTA, 2008a).

A relação entre segurança e mudanças climáticas tem como objetivo "o investimento na mitigação para evitar esses cenários [de segurança sem precedentes] e a procura de formas de adaptação ao inevitável que deverão ir ao encontro da adoção de medidas para enfrentar as ameaças à segurança internacional ocasionadas pelas alterações climáticas; estes dois aspectos devem ser considerados parte integrante de uma política de segurança preventiva" (COMISSÃO EUROPEIA, 2007, p. 1). Trata-se, portanto, de uma renegociação do espaço na qual a administração de riscos e os mecanismos de mercado prevalecem, cujas consequências dependem do objeto a ser securitizado, dos meios empregados para a provisão de segurança e da lógica de segurança que informa tal processo.

Nesse sentido, o que o movimento de securitização das mudanças climáticas sugere é o deslocamento da lógica de segurança de uma perspectiva tradicionalista para uma lógica em "harmonia com o conceito de segurança humana" (COMISSÃO EUROPEIA, 2008, p. 2), envolvendo questões "interligadas e que requerem respostas políticas abrangentes" (COMISSÃO EUROPEIA, 2008, p. 2). Por sua vez, tais discursos trazem consigo também uma abordagem baseada na prevenção de conflitos, amplamente inspirada pelo princípio da precaução, característico das práticas e normas ambientais (TROMBETTA, 2008b). O que estes discursos, designadamente liderados pela UE, sugerem é a criação, em escala internacional, de mecanismos de governança em segurança similares aos mecanismos que governam a política doméstica. Com isso, pretende-se também uma provável relativização entre segurança e meios militares, influenciada principalmente pela UE, em função da sua disposição limitada de recursos militares (TROMBETTA, 2008b).

Na medida em que tais reflexões são realizadas a partir dos problemas ambientais, tais práticas de segurança, consideradas como ines- 
capáveis e imutáveis, podem ser relativizadas, visto que até mesmo Buzan et al. (1998, p. 71) reconhecem que este setor "indetermina quais tipos de estruturas políticas as preocupações ambientais irão gerar". Neste sentido, "essa tensão pode ser amenizada, visto que [de acordo com os próprios teóricos de Copenhague] tentativas de securitizar o meio ambiente são descritas como tendo um potencial transformativo exigindo e clamando por novas instituições" (TROMBETTA, 2006, p. 11). Por conseguinte, os movimentos de securitização no setor ambiental parecem exprimir um potencial transformativo, contrastante com o potencial conservador de outros setores. Todos os aspectos levantados permitem afirmar que a securitização das mudanças climáticas tem transformado as práticas de segurança, sugerindo que "a abordagem da segurança humana emerge como uma alternativa genuína para a abordagem de securitização" (FLOYD, 2008, p. 42), no sentido de complementá-la.

Não obstante a emergência de práticas alternativas de segurança, é preciso esclarecer que o uso do slogan "segurança" remete a uma discussão que supera o problema da natureza da segurança e se associa à questão da escolha política, em que pesam modos específicos de encaminhamento, baseados tanto no binômio ameaça/defesa quanto em medidas human-centred. Nesse sentido, não se pode descartar a adoção de medidas vinculadas à exigência de soluções centradas no Estado, que conduziriam a efeitos pouco desejáveis para a agenda ambiental (WAEVER, 1995a), isso porque "o conceito de segurança [ainda] dá a entender que a defesa de um problema tem que ser sustentada pelo Estado" (WAEVER, 1995a, p. 63), afastando assim a possibilidade de organizações especializadas darem respostas a estes problemas, além de induzir à militarização das questões ambientais. Além disso, cumpre destacar que a securitização das mudanças ambientais não descarta a possibilidade de a política ambiental ser tratada a partir da dicotomização do tipo nós-eles, inserindo as questões ambientais em uma lógica nacionalista. Nesse sentido, Waever, para- 
Securitização das Mudanças Climáticas: 0

Papel da União Europeia

fraseando Deudney, afirma que “a 'nação' não é um recipiente ou uma lousa vazia aguardando para ser preenchida ou escrita, mas está, em substituição, profundamente ligada à guerra e ao pensamento nós versus eles" (DEUDNEY, 1991 apud WAEVER, 1995a, p. 64). Essa tendência nacionalista, salienta Waever (1995a), aponta também para a possibilidade de um determinado Estado isentar-se da responsabilidade pelos danos causados ao meio ambiente, já que a incumbência por tais danos recairia sobre o outro, levando a questão ambiental a um impasse.

Finalmente, destaca Waever (1995a), é preciso refletir sobre os riscos da segurança ambiental, na medida em que esta pode se tornar uma ferramenta perigosa na mão de uma esquerda totalitária, que pode tentar se relançar sob a égide do coletivismo ambiental.

Consequentemente, para Waever (1995a), o uso do slogan "segurança ambiental", apesar de parecer tentador em um primeiro momento, pode "conduzir a uma construção social inadequada do meio ambiente como uma questão de ameaça/defesa" (WAEVER, 1995a, p. 65). Portanto, a securitização do meio ambiente, em geral, e das mudanças climáticas, em particular, guarda consigo uma tentativa permanente de manutenção de equilíbrios instáveis entre uma lógica antagonista de um lado e uma lógica human-oriented de outro.

\section{Considerações Finais}

A discussão sobre como se dá o processo de construção das mudanças climáticas como um problema de segurança pela UE deu origem a outra inquietação relativa à perspectiva da segurança humana, cujo propósito é a adoção de uma abordagem preventiva, amparada por políticas de mitigação e adaptação às consequências das mudanças climáticas, bem como pelo fortalecimento de acordos multilaterais. Diferentemente de uma abordagem que aponte para a impossibilidade de estar preparado para todas as ameaças potenciais, a abordagem 
adotada pela UE adverte para os impactos catastróficos das ameaças climáticas, sugerindo a adoção de medidas de adaptação e mitigação, orientadas por uma racionalidade de ação preventiva. Nesse sentido, a securitização das mudanças climáticas pela UE sugere uma transformação no debate sobre o tema, que deixou de pertencer exclusivamente ao campo da cooperação para integrar o campo da segurança internacional.

Apesar de a crença na possibilidade de ganhos cooperativos progressivos provenientes da relação entre mudanças climáticas e segurança ter sido contestada pelos países em desenvolvimento, bem como pelos Estados Unidos, nos discursos no Conselho de Segurança é provável que tal estratégia, adotada principalmente pelos europeus, alcance seus objetivos. Isso porque as implicações de segurança das mudanças climáticas para a Europa, bem como para os países subdesenvolvidos e insulares, são suficientemente vultosas para desencadear maior abertura política e multilateral necessária ao tratamento do problema em escala global.

Não resta dúvida de que os atores securitizadores se empenharam para levar o Conselho a reconhecer os vínculos entre novos fenômenos emergentes em escala internacional e as questões de segurança. Ressalta-se o modo como a identificação de ameaças diz muito a respeito das identidades, interesses e valores protegidos pelos atores, bem como das práticas e lógicas associadas à segurança. Com isso, a exploração das características peculiares de cada discurso sobre a securitização do clima se revelou significativa. Em primeiro lugar, esses discursos indicaram uma preocupação com a segurança do clima, que pode ser entendida como a manutenção da estabilidade climática enquanto condição prévia para a "conservação de níveis de civilização adquiridos” (BUZAN et al., 1998, p. 76). Dado que o modo de vida contemporâneo vem causando problemas ambientais de proporções globais, paira no ar o dilema: para preservar as estruturas político-econômicas e socioculturais das sociedades em escala local, naci- 
Securitização das Mudanças Climáticas: 0

Papel da União Europeia

onal e mundial, é necessário alterá-las fundamentalmente, dada a sua insustentabilidade. Sendo assim, ou essas estruturas são modificadas de forma voluntária e controlada ou serão transformadas de maneira violenta e ao acaso pelas crises ambientais (WILDE, 2008). No caso das mudanças climáticas, este dilema se torna muito mais penoso, em função da urgência envolvida nas ações de combate, uma vez que seus danos são cumulativos e só são percebidos em longo prazo.

Nesse sentido, esse dilema atinge o núcleo de toda a discussão, remetendo novamente à existência de duas abordagens contrastantes acerca da provisão de segurança. A primeira, dependente de medidas emergenciais, sugere a impossibilidade de se estar preparado para todas as potenciais ameaças advindas das mudanças climáticas. A segunda desenvolve-se a partir de uma abordagem preventiva e adverte para os impactos catastróficos das mudanças climáticas (TROMBETTA, 2008b). Esse debate traz consigo, assim, a possibilidade de transformar em ameaça um fenômeno que ainda não foi materializado, influenciando as práticas sugeridas pela Escola de Copenhague e revelando, assim, os limites e as possibilidades do conceito de segurança na abordagem deste problema.

A alusão a um problema de segurança nesse caso, relacionada à deflagração de conflitos, tem feito com que a UE invista em medidas estruturais e alternativas que incluem uma abordagem preventiva, o fortalecimento do multilateralismo e o fomento à diplomacia preventiva. Outra característica peculiar da análise de securitização é que muitos movimentos securitizadores das mudanças climáticas resultaram na sua politização. Conforme argumenta Trombetta (2006), esse desenvolvimento é problemático para a Escola de Copenhague, na medida em que seus autores afirmam que "transcender um problema de segurança pela politização deste não pode acontecer por meio da tematização em termos de segurança, somente em direção oposta a tais termos" (WAEVER, 1995a, p. 56). Isso porque, uma vez que uma questão é inscrita em uma lógica antagonista, é muito difícil re- 
torná-la ao debate aberto novamente. Apesar disso, "as várias politizações das questões ambientais que seguiram o apelo à segurança aquelas que a Escola de Copenhague rejeita, definindo como securitizações falidas - parecem reforçar o argumento, sugerido por Edkins (1999), de que é uma tendência politizar questões por meio de sua securitização" (TROMBETTA, 2006, p. 11). Por sua vez, essa questão sugere que a securitização no setor ambiental pode admitir formas distintas, demonstrando que evocar segurança neste setor não parece tão problemático quanto Buzan et al. (1998) afirmam ser. Por conseguinte, essa tensão existente entre o que preconiza a teoria e o que foi observado empiricamente conduziu este trabalho a um impasse: seria a securitização das mudanças climáticas bem-sucedida ou falida?

Mesmo que a Escola de Copenhague defina as tentativas de securitização do meio ambiente, em geral, como malsucedidas, há que se considerar que a transformação de uma questão em problema de segurança pode ser orientada por diferentes modalidades e lógicas, que escapam à lógica antagonista do modelo de segurança nacional, sugerida pela Escola. Por meio do apelo à segurança, outras lógicas, características de contextos distintos, podem emergir e novos atores podem adquirir relevância na política de segurança. Apelos bem-sucedidos à segurança exigem o desenvolvimento de políticas de segurança, por meio da identificação de estratégias e de meios adequados para lidar com o problema que, por sua vez, são amplamente ancorados nas características de cada setor, com referências, valores e práticas distintas. Assim, "a teoria dos atos de fala implica na possibilidade de argumento, de diálogo, e por meio disso estende o potencial para a transformação das percepções de segurança, dentro e entre Estados" (WILLIAMS, 2003, p. 523).

Nesse sentido, a emergência de novas ameaças tem sugerido que a adoção de medidas reativas baseadas em um entendimento antagonista de segurança não constitui a única forma de lidar com as amea- 
Securitização das Mudanças Climáticas: 0

Papel da União Europeia

ças apresentadas pelas mudanças climáticas. Em vez disso, medidas preventivas parecem emergir como alternativa, tornando práticas como a administração de riscos, a prevenção de conflitos e o multilateralismo respostas prováveis à discussão sobre segurança e mudanças climáticas (TROMBETTA, 2008a).

Portanto, a "securitização pode ser considerada como um processo reflexivo, que não é somente orientado por regras [rule-directed], mas também transformador de regras [rule altering]" (TROMBETTA, 2008a, p. 591). Nesse sentido, a securitização não se refere ao uso de um significado fixo de segurança como excepcionalismo, como sugere Waever (1995a); pelo contrário, segurança sugere um processo interativo e localizado de produção de significados (STRITZEL, 2007; TROMBETTA, 2008a).

\section{Notas}

1. Esta e as demais citações de originais em língua estrangeira foram livremente traduzidas para este artigo.

2. Ver, por exemplo, CNA (2007), Brauch (2007), IPCC (2007) e Stern Review (2006).

3. Continuum de segurança são equivalências retóricas criadas a partir de um sentimento de insegurança que acaba por ofuscar as tensões entre segurança interna e externa, política e militar etc., tornando questões tais como imigrações, crime organizado, terrorismo e degradação ambiental equivalentes tanto em documentos, quanto em discursos oficiais, sem justificativa. 


\section{Referências} Bibliográficas

BARNETT, Jon. The meaning of environmental security: ecological politics and policy in the new security era. New York: Zed Books, 2001.

BRAUCH, Hans Günter. Environmental and human security. Towards freedom from hazard impacts. Hexagon, fev. 2005. Disponível em: $<$ http://hexagon-series.org/html/download_hgb.html>. Acesso em: 20 set. 2008.

Introduction: globalization and environmental challenges: reconceptualizing security in the 21 st century. In: BRAUCH, H. G.; OSWALD SPRING, Ú.; MESJASZ, C.; GRIN, J.; DUNAY, P.; BEHERA, N. C.; CHOUROU, B.; KAMERI-MBOTE, P.; LIOTTA, P. H (Ed.). Globalization and environmental challenges: reconceptualizing security in the 21st century. New York: Springer, 2008. p. 27-44.

BROWN, Lester. Redefining national security. Washington: Worldwatch Institute, 1977.

BUZAN, Barry. Rethinking security after the Cold War. Cooperation and Conflict, v. 32, n. 1, p. 5-28, 1997.

; WAEVER, Ole. Macrosecuritisation and security constellations: reconsidering scale in securitisation theory. Review of International Studies, v. 35, n. 2, p. 253-276, 2009.

; WILDE, Jaap de. Security: a new framework for analysis. Boulder: Lynne Rienner Publishers Inc, 1998.

CMMAD - Comissão Mundial sobre Meio Ambiente e Desenvolvimento. Nosso futuro comum. Rio de Janeiro: Fundação Getulio Vargas, 1991.

CNA - Center for Naval Analysis. National security and the threat of climate change. CNA Corporation, 2007. Disponível em: <http://www.cna.org >. Acesso em: 28 jul. 2008.

COMISSÃO EUROPEIA. Combating climate change: the EU leads the way. Europa, 2007. Disponível em: <http://ec.europa.eu/publications/booklets/ move/70/en.pdf>. Acesso em: 21 abr. 2009. 
Securitização das Mudanças Climáticas: 0

Papel da União Europeia

Alterações climáticas e segurança internacional. Documento do Alto Representante e da Comissão Europeia para o Conselho Europeu. Consilium, 2008. Disponível em: <http://www.consilium.eu.int/uedocs/cms_data/librairie/PDF/PT_clim_change_low.pdf>. Acesso em: 23 abr. 2009.

CONSELHO DA UNIÃO EUROPEIA. Relatório sobre a execução da estratégia europeia de segurança - garantir a segurança num mundo em mudança. Consilium, 2008. Disponível em: <http://www.consilium.europa.eu/ueDocs/ cms_Data/docs/pressdata/PT/reports/104638.pdf>. Acesso em: 18 abr. 2009.

DABELKO, G. D. State of art review of environment, security and development cooperation. OECD, 2000. Disponível em: <http://www.oecd.org/dataoecd/8/51/2446676.pdf>. Acesso em: 6 nov. 2008.

EUROBARÔMETRO. The European citizens and the future of Europe: qualitative study in 25 members States. European Comission Public Opnion, mai. 2006. Disponível em: <http://ec.europa.eu/public_opinion/quali/ql_futur_ en.pdf>. Acesso em: 10 mai. 2009.

. Europeans' attitudes towards climate change. European Comission Public Opnion, jul. 2008. Disponível em: <http://ec.europa.eu/public_opinion/archives/ebs/ebs_300_full_en.pdf>. Acesso em: 12 mai. 2009.

FLOYD, Rita. The environmental security debate and its significance for climate change. The International Spectator, v. 43, n. 3, p. 51-65, 2008.

HUYSMANS, Jef. Revisiting Copenhagen: or, on the creative development of security studies agenda in Europe. European Journal of International Relations, v. 4, n. 4, p. 479-505, 1998.

. Defining social constructivism in security studies: the normative dilemma of writing security. Alternatives, v. 27, Special Issue, p. 41-62, 2002.

IPCC - Intergovernamental Panel of Climate Change. Climate change 2007: synthesis report, summary for policymakers. IPCC, 2007. Disponível em: $<$ http://www.ipcc.ch/pdf/assessment-report/ar4/syr/ar4_syr_spm.pdf $>$. Acesso em: 19 set. 2008 .

IPSOS MORI. Tipping point or turning point? Social marketing and climate change. Ipsos Mori, 24 jul. 2007. Disponível em: <http://www.ipsos-mori. com/_assets/reports/turning-point-or-tipping-point.pdf>. Acesso em: 12 mai. 2009. 
MATHEWS, Jessica T. Redefining security. Foreign Affairs, v. 68, n. 2, p. 162-177, 1989.

MYERS, Norman. Environment and security. Foreign Policy, v. 74, p. 23-41, 1989.

OBERTHÜR, Sebastian; KELLY, Claire Roche. EU leadership in international climate policy: achievements and challenges. The International Spectator, $\mathrm{v}$. 43, n. 3, p. 35-50, 2008.

PAGE, Eduard. Theorizing the link between environmental change and security. Reciel, v. 9, n. 1, p. 33-43, 2000.

SECURITY COUNCIL. 5663 rd meeting. United Nations, 17 abr. 2007a. Disponível em: <http://www.un.int/wcm/webdav/site/tuvalu/shared/documents/ SC/N0730908.pdf>. Acesso em: 23 abr. 2009.

5663 rd meeting. United Nations, 17 abr. 2007b. Disponível em: <http://www.un.int/wcm/webdav/site/tuvalu/shared/documents/ SC/N0730973.pdf>. Acesso em: 22 abr. 2009.

STERN REVIEW. The economics of climate change. HM Treasury, 2006. Disponível em: <http://www.hm-treasury.gov.uk/sternreview_index.htm>. Acesso em: 14 dez. 2008.

STRITZEL, Holger. Towards a theory of securitization: Copenhagen and beyond. European Journal of International Relations, v. 13, n. 3, p. 357-383, 2007.

TRANSATLANTIC TRENDS. Key findings 2007. The German Marshall Funds of United States, 2007. Disponível em: <http://www.transatlantictrends.org/trends/index.cfm?year=2007>. Acesso em: 12 mai. 2009.

TRENELL, Paul. The (im)possibility of environmental security. 2006. Dissertação (Mestrado em Estudos de Segurança) - University of Wales, Aberystwyth, 2006. Disponível em: <http://cadair.aber.ac.uk/dspace/handle/ 2160/410>. Acesso em: 30 set. 2008.

TROMBETTA, Maria Julia. The securitization of the environment and the transformation of security. Standing Group on International Relations Conference, Turin, 2006. Disponível em: <http://archive.sgir.eu/uploads/Trombetta-the_securitization_of_the_environment_and_the_transformation_of_security.pdf>. Acesso em: 15 ago. 2008. 
Securitização das Mudanças Climáticas: 0

Papel da União Europeia

. The meaning and function of climate security. Global International Studies Conference, Eslovênia, n. 2, 2008a. Disponível em: <http://www.wiscnetwork.org/ljubljana2008/getpaper.php?id=139>. Acesso em: 12 fev. 2009.

Environmental security and climate change: analysing the discourse. Cambridge Review of International Affairs, v. 21, n. 4, p. 585-602, 2008b.

ULLMAN, Richard H. Redefining security. International Security, v. 8, n. 1, p. 129-153, 1983.

UNEP - United Nations Environmental Programme. Young people urge world leaders to combat climate change. UNEP, 2008. Disponível em: $<$ http://www.unep.org/pdf/survey_results.pdf>. Acesso em: 14 mai. 2009.

VAN DIJCK, Dominique. Is the EU policy on illegal immigration securitized? Yes of course! Pan-European Conference on EU Politics, Istambul, n. 3, 2006. Disponível em: <http://www.jhubc.it/ecpr-istanbul/virtualpaperroom/ 054.pdf>. Acesso em: 16 ago. 2008.

WAEVER, Ole. Securitization and desecuritization. In: LIPSCHUTZ, R. D. (Ed.). On security. New York: Columbia University Press, 1995a. p. 46-86.

. Concepts of security - the state of play; and a plea for the midmost concept. In: Concepts of security. Copenhagen: Institute of Political Science, $1995 b$.

All dressed up and nowhere to go? Securitization of climate change. ISA Annual Convention, New York, n. 50, 2009. Disponível em: <http://www. allacademic.com/meta/p_mla_apa_research_citation/3/1/ 1/8/9/p311899_ index.html>. Acesso em: 1ำ mai. 2009.

WENDT, Alexander. Social theory of international politics. Cambridge: Cambridge University Press, 1999.

WILDE, Jaap de. Environmental security desconstructed. In: BRAUCH, H. G.; OSWALD SPRING, Ú.; MESJASZ, C.; GRIN, J.; DUNAY, P.; BEHERA, N. C.; CHOUROU, B.; KAMERI-MBOTE, P.; LIOTTA, P. H. (Ed.). Globalization and environmental challenges: reconceptualizing security in the 21 st century. New York: Springer, 2008. p. 595-602.

WILLIAMS, Michael C. Words, images, enemies: securitization and international politics. International Studies Quartely, v. 47, n. 4, p. 511-531, 2003. 


\section{Resumo}

\section{Securitização das Mudanças Climáticas: O Papel da União Europeia}

Este trabalho busca analisar o "movimento de securitização" das mudanças climáticas no sistema internacional, a partir da ação da União Europeia como ator secutirizador. A partir das discussões de Buzan, Waever e Wilde, busca-se compreender o processo de construção de ameaças no campo ambiental. Tomam-se como ponto de partida as definições e critérios estabelecidos pela União Europeia como ator securitizador, ao enunciar as mudanças climáticas como uma ameaça existencial à segurança internacional na reunião do Conselho de Segurança ocorrida em 2007. São analisadas, também, as repercussões dos atos de fala securitizadores entre os Estados presentes, aqui entendidos como audiência. O principal método adotado para a realização deste trabalho foi a análise de discurso, tendo como fonte principal os documentos oficiais e pronunciamentos de autoridades governamentais, divulgados tanto pelo Conselho de Segurança como pela União Europeia.

Palavras-chave: Mudanças Climáticas - Segurança Internacional - Securitização - União Europeia

\section{Abstract}

\section{Securitization of Climate Change: The Role of European Union}

This work aims to analyse the "securitisation movement" of the climate change in the international system, taking the European Union as a securitising actor. From Buzan's, Waever's and Wilde's discussions, one shall understand the process of threat construction in the environmental field. The definitions and criteria established by the European Union as a securitising actor are taken as starting point, when climate changes were annouced as an existing threat to the international security at a Security Council's meeting held in 2007. The impacts of the securitising speech acts amongst the present states, here undertood as the audience, will also be taken into account. The main method chosen to guide this work was the 
Securitização das Mudanças Climáticas: 0

Papel da União Europeia

speech analysis, having as the main source the official documents and government authorities statements disclosed both by the Security Council and the European Union.

Keywords: Climate Change - International Security - Securitization European Union 